\title{
Survey of Dynamic Simulation Programs for Nuclear Fuel Reprocessing
}

\author{
Troy J. Tranter \\ Daryl R. Haefner \\ June 2008
}

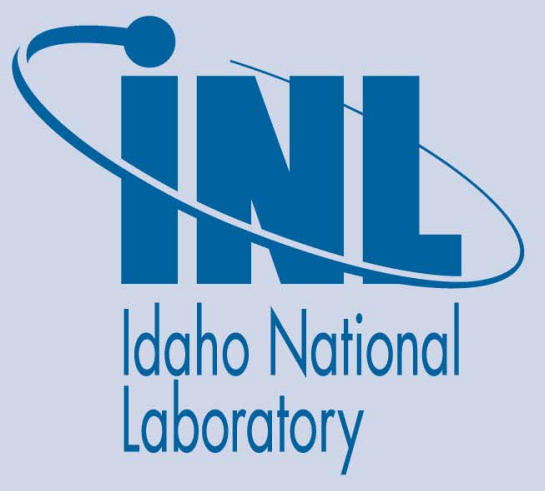

The INL is a U.S. Department of Energy National Laboratory operated by Battelle Energy Alliance 


\title{
Survey of Dynamic Simulation Programs for Nuclear Fuel Reprocessing
}

Troy J. Tranter

Daryl R. Haefner

June 2008

\begin{abstract}
Idaho National Laboratory
Idaho Falls, Idaho 83415
\end{abstract}

Prepared for the

U.S. Department of Energy

Office of Nuclear Energy

Under DOE Idaho Operations Office

Contract DE-AC07-05ID14517 


\section{DISCLAIMER}

This information was prepared as an account of work sponsored by an agency of the U.S. Government. Neither the U.S. Government nor any agency thereof, nor any of their employees, makes any warranty, expressed or implied, or assumes any legal liability or responsibility for the accuracy, completeness, or usefulness, of any information, apparatus, product, or process disclosed, or represents that its use would not infringe privately owned rights. References herein to any specific commercial product, process, or service by trade name, trade mark, manufacturer, or otherwise, does not necessarily constitute or imply its endorsement, recommendation, or favoring by the U.S. Government or any agency thereof. The views and opinions of authors expressed herein do not necessarily state or reflect those of the U.S. Government or any agency thereof. 



\section{SUMMARY}

The purpose of this document is to provide a brief survey of the dynamic simulation computer codes that have been developed for modeling countercurrent solvent extraction processes specific to nuclear fuel reprocessing. This report is intended to be a summary of applicable codes as opposed to a thorough review of the field; however it is an important step in assessing the current simulation capability and to define a proper path forward. The primary focus is to identify simulation packages or codes that have been developed to incorporate dynamic capability, i.e., the ability to estimate or predict temporal behavior of the solvent extraction system during transients as well as steady-state. A review of publicly available literature indicates that there are only two simulation codes that have been developed with dynamic capability and then validated to any significant degree against actual data from operating fuel separation and recovery processes. Brief descriptions of the dynamic simulations packages follow. Though it does not meet the criterion for a dynamic modeling code, one steady-state simulation package is also mentioned because of its merit and current use among flowsheet developers in the nuclear processing and separations sciences. 


\section{CONTENTS}

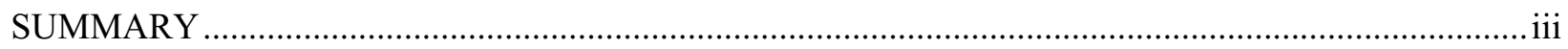

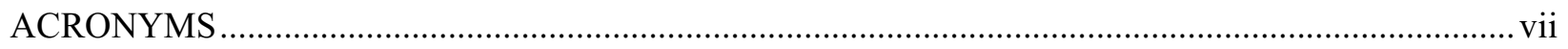

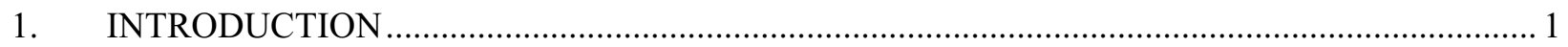

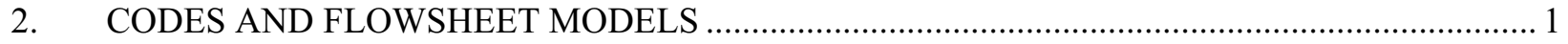

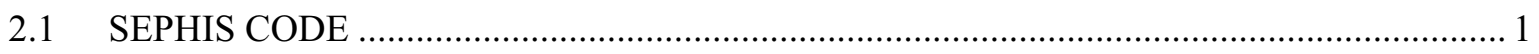

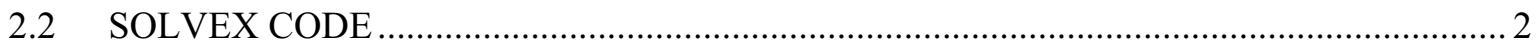

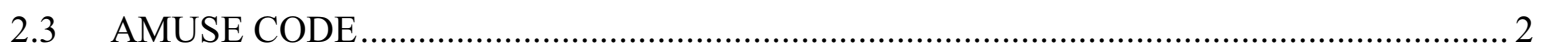

2.4 FLOWSHEET MODELING AND SIMULATION PACKAGES …..................................... 3

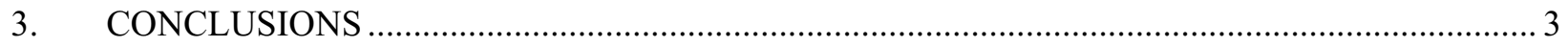

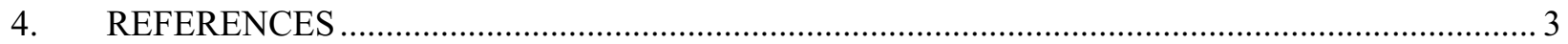




\section{ACRONYMS}

AMUSE Argonne Model for Universal Solvent Extraction

gPROMS general Process Modelling System

NEA Nuclear Energy Agency

PSE Process Systems Enterprise

SASPE Spreadsheet Algorithm for Speciation and Partitioning Equilibria

SASSE Spreadsheet Algorithm for Stagewise Solvent Extraction

SEPHIS Solvent Extraction Process Having Interaction Solvents 


\section{Survey of Dynamic Simulation Programs for Nuclear Fuel Reprocessing}

\section{INTRODUCTION}

The current U.S. vision of the next generation advanced nuclear fuel cycle for the commercial nuclear power industry includes a series of aqueous separation steps based on solvent extraction technologies, which fractionate dissolved nuclear fuel into discrete product streams for storage, reuse, or disposal. Several options for this processing scheme exist, including various UREX options, and other process combinations for separating actinides, lanthanides and fission products. The technical complexities (e.g., process upsets and perturbations due to feed and process inconsistencies) of operating such a complex system are as varied as the drivers for the separations themselves (e.g., energy recovery, repository capacity and proliferation resistance). Development of dynamic process models are an important aspect of understanding and predicting the inherent transient behavior of such a complex series of unit operations, and ultimately for the entire process from spent fuel receipt to waste treatment and disposal. Exponential cost increases in conducting experimental and pilot scale programs have forced researchers to work "smarter"; conversely, there have been dramatic enhancements in sophistication and reduced costs of available computer codes and computing power. Capitalizing on the latter can substantially augment the former by using computational methods to guide and minimize the amount of experimental and piloting work required to develop and understand complex systems or processes. This fact is exploited in many engineering fields and industry where computer simulations are routinely performed in lieu of pilot or semi-scale tests.

The purpose of this effort is to provide a brief survey of the dynamic simulation computer codes that have been developed for modeling countercurrent solvent extraction processes specific to nuclear fuel reprocessing. This report is intended to be a summary of applicable codes as opposed to a thorough review of the field; however it is an important step in assessing the current simulation capability and to define a proper path forward. The primary focus is to identify simulation packages or codes that have been developed to incorporate dynamic capability, i.e., the ability to estimate or predict temporal behavior of the solvent extraction system during transients as well as steady-state. A review of publicly available literature indicates that there are only two simulation codes that have been developed with dynamic capability and then validated to any significant degree against actual data from operating fuel separation and recovery processes. Brief descriptions of the dynamic simulations packages follow. Though it does not meet the criterion for a dynamic modeling code, one steady-state simulation package is also mentioned because of its merit and current use among flowsheet developers in the nuclear processing and separations sciences.

\section{CODES AND FLOWSHEET MODELS}

\subsection{SEPHIS CODE}

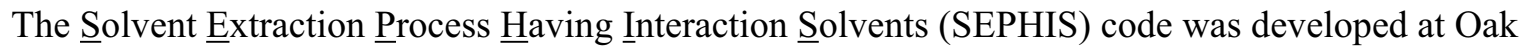
Ridge National Laboratory for modeling multistage, countercurrent flowsheets for the PUREX solvent extraction process. It was developed for systems using mixer-settler contactors to predict transient and steady-state concentrations of major components. It is written in FORTRAN code, and like most transient simulations, relies on mass balance calculations over specified dimensions to maintain continuity requirements. The calculations proceed at selected time intervals until convergence is reached, i.e., the change between successive calculations meets a user-defined minimum tolerance considered to approximate steady-state conditions. According to available literature, the SEPHIS-MOD4 program 
appears to be the most recent revision (Mitchell 1979). The original, SEPHIS-MOD1, was written specifically to provide a model for predicting time-dependent behavior of the PUREX solvent extraction process (Groenier 1972). Improvements were made to the program as SEPHIS-MOD2 and MOD3 wherein the rigor of the algorithms used for equilibrium distribution calculations were enhanced with better correlation factors and provisions for handling salting effects of inextractable species and plutonium reduction (Richardson 1973, Richardson 1975, Watson, 1975). The work in SEPHIS-MOD4 again resulted in several improvements to previous versions. The algorithms for calculating chemical equilibrium were improved by adding integrated forms of kinetic equations to account for time dependency of plutonium reduction reactions. The settler region was divided into three consecutive zones and the Runge-Kutta numerical integration scheme is used to estimate concentration changes with time at the boundaries of the zones. The SEPHIS-MOD4 simulation package has been tested using pilot-scale and process contactors (Kyser 1998, Rodrigues 1983) and has been shown to be of reasonable utility as long as the user understands its inherent limitations. It has proven to be a useful simulator; however it has limitations that are primarily due to the lack of computational resources available at the time it was developed. The limiting aspects of the SEPHIS-MOD4 code are:

- Outdated user interface (written in FORTRAN)

- Developed to model mixer-settlers with little spatial resolution

- Assumes equilibrium in each stage, i.e., 100\% stage efficiency

- Does not account for any mass transfer in the phase separation (settling) zone

- Specific to PUREX process solvent extraction flowsheets.

\subsection{SOLVEX CODE}

A computer program for the simulation of solvent extraction processes (SOLVEX) was developed by Savannah River Laboratory (Scotten 1975). The SOLVEX program was designed to simulate transient and steady-state behavior in a general solvent extraction system. The conceptual model is very similar to that used by the SEPHIS-MOD4 program. Similar to SEPHIS-MOD4 code, SOLVEX is written in FORTRAN, is designed for mixer-settler contactor systems and requires user-defined tolerances for determining convergence; however, the SOLVEX program does have a few key differences. The SOLVEX program allows the user to divide the settler region into any number of discrete zones to provider finer adjustment between plug and mixed flow. The equations used to simulate solute movement through the contactors are solved via algorithms based on finite difference methods. The program is also intended to accommodate different solvent extraction systems and therefore the user must provide tables of the applicable distribution coefficients or equations for calculating the same.

\subsection{AMUSE CODE}

The Argonne Model for $\underline{\text { Universal }} \underline{\text { Solvent }} \underline{\text { Extraction }}$ (AMUSE) code was originally developed at Argonne National Laboratory to design multistage countercurrent flowsheets for the TRUEX solvent extraction process. The AMUSE code is actually composed of two major sections. The $\underline{\text { Spreadsheet }}$

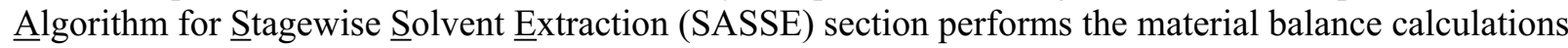

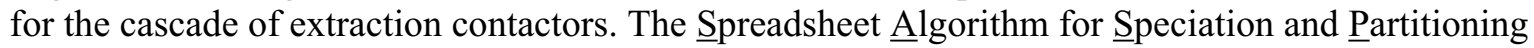
Equilibria (SASPE) estimates the distribution ratios for each contactor based on input compositions and conditions of the aqueous and organic phases in each contactor. The SASSE and SASPE sections interact via Microsoft Excel to generate the overall process model. When the AMUSE code calculates a flowsheet, the SASPE section supplies distribution values to the SASSE section of the code, which then refines the calculated distribution values until the desired convergence criteria is achieved. The AMUSE code provides a steady state model of extraction processes (Leonard 1994, Regalbuto 2004). 


\subsection{FLOWSHEET MODELING AND SIMULATION PACKAGES}

Commercial flowsheet packages such as ASPEN, PRO II, and CHEMCAD are designed to build process flowsheets from a library of unit operation models (Hangos 2001). These simulations typically perform steady state process modeling, however ASPEN does have two tools that can be used to perform dynamic modeling: ASPEN Dynamics ${ }^{\circledR}$ and ASPEN Custom Modeler ${ }^{\circledR}$. A review of recent literature has found several applications of ASPEN Dynamics ${ }^{\circledR}$ and ASPEN Custom Modeler $®$ on various processes (adsorption, chromatography, distillation) and even batch processing of actinides, but none for multistage solvent extraction (Hang 2003, Luyben 2006). Conceptually, a flowsheet with a series of solvent extraction contactors operating in steady state could be simulated using ASPEN Plus, and then the system perturbed and the dynamics analyzed using ASPEN Dynamics ${ }^{\circledR}$ and/or ASPEN Custom Modeler ${ }^{\circledR}$ (AspenTech 2008). Information specific to the solvent system would have to be incorporated in the ASPEN model, which for a PUREX type system could be provided by the AMUSE code.

Process Systems Enterprise has developed a modeling and simulation software package called gPROMS (general Process Modelling System), which has extensive capabilities for modeling chemical processes and includes the option for dynamic modeling. The user defines the chemical system by a set of mathematical equations (time varying for dynamic systems), which are then solved numerically for the parameters of interest (PSE 2008). Several articles in the recent literature confirm the utility of gPROMS in dynamic modeling of systems (Alonso 1999, Asteasuain 2001, Byoungmu 1998). Although no published articles were found for its use in modeling multistage solvent extraction, gPROMS presumably could be used for this application.

\section{CONCLUSIONS}

The absence of any industrial scale nuclear fuel reprocessing in the U.S. has precluded the necessary driver for developing the advanced simulation capability now prevalent in so many other industries. Modeling programs to simulate the dynamic behavior of nuclear fuel separations and processing were originally developed to support the US government's mission of weapons production and defense fuel recovery. Consequently there has been little effort is the US devoted towards improving this specific process simulation capability during the last two or three decades. More recent work has been focused on elucidating chemical thermodynamics and developing better models of predicting equilibrium in actinide solvent extraction systems (Baes 2001). These equilibrium models have been used to augment flowsheet development and testing primarily at laboratory scales. The development of more robust and complete process models has not kept pace with the vast improvements in computational power and user interface and is significantly behind simulation capability in other chemical processing and separation fields.

\section{REFERENCES}

Alonso, Ana I., Berta Gala' n, Manuel Gonza' lez, and Inmaculada Ortiz, "Experimental and Theoretical Analysis of a Nondispersive Solvent Extraction Pilot Plant for the Removal of Cr(VI) from a Galvanic Process Wastewaters," Ind. Eng. Chem. Res., Vol. 38, 1999, pp. 1666-1675.

Asteasuain, M., S. M. Tonelli, A. Brandolin, J. A. and Bandoni, "Dynamic simulation and optimisation of tubular polymerisation reactors in gPROMS," Computers and Chemical Engineering, Vol. 25, Issues 4-6, May 2001, pp. 509-515.

Baes Jr., C. F. (2001), "Modeling Solvent Extraction Systems with SXFIT," Solvent Extraction and Ion Exchange, 19:2, 2001, pp. 193-213.

Byoungmu, C.; L. Seunghoon, K. Hyeoktae, and M. Il, "Rigorous Industrial Dynamic Simulation of a Crude Distillation Unit Considered Valve Tray Rating Parameters," Computers and Chemical Engineering, Vol. 22, Supplement 1, May 1998, pp. 863-866. 
AspenTech website, accessed June 26, 2008: www.aspentech.com.

Hangos, Katalin M., and I. T. Cameron, Process Modelling and Model Analysis, Academic Press, 2001.

Hang, T., "A Dynamic Model of the Actinide Removal Process at the Savannah River Site," paper proposed for the SCS Advanced Simulation Technologies Conference, Arlington, VA, April 18-22, 2004.

Groenier, W. S., Calculation of the Transient Behavior of a Dilute PUREX Solvent Extraction Process having Application to the Reprocessing of LMFBR Fuels, ORNL-4746, April 1972.

Kyser, Edward A., Validation of the SEPHIS Program for the Modeling of the HM Process, Savannah River Site Report WSRC-TR-98-O0376, Aiken, South Carolina, October 1998.

Leonard, Ralph A., and M. C. Regalbuto, "A Spreadsheet Algorithm for Stagewise Solvent Extraction," Sol. Extr. And Ion Exch., 12(5), 1994, pp. 909-930.

Luyben, William L., Distillation Design and Control Using Aspen Simulation, Lavoisier Press, 2006.

Mitchell, A. D., A comparison between SEPHIS-MOD4 and previous models of the PUREX solvent extraction system, Oak Ridge National Laboratory Report QRNL/TM-6565, Oak Ridge, TN, February 1979.

Process Systems Enterprise (PSE) website, accessed June 27, 2008: www.psenterprise.com.

Regalbuto, M. C., J. M. Copple, R. Leonard, C. Pereira, and G. F. Vandegrift, "Solvent Extraction Process Development for Partitioning and Transmutation of Spent Fuel," OECD Nuclear Energy Agency (NEA), Actinide and Fission Product Partitioning \& Transmutation, Eighth Information Exchange Meeting, Session II: Partitioning and Waste Management, Las Vegas, Nevada, USA November 2004.

Richardson, G. L., Effect of High Solvent Irradiation Exposures on TBP Processing of Spent LMFBR Fuels, Hanford Engineering Development Laboratory, HEDL-TME 73-51, June 1973.

Richardson, G. L., and J. L. Swanson, Plutonium Partitioning in the PUREX Process with Hydrazine-Stabilized Hydroxylamine Nitrate, Hanford Engineering Development Laboratory, HEDL-TME 75-31, June 1975.

Rodrigues, G. C., and A. P. Gouge, Reprocessing RERTR Silicide Fuels, Savannah River Laboratory, DP1657, May 1983.

Scotten, W.C., SOLVEX - A Computer Program for Simulation of Solvent Extraction Processes, DP-1391, September 1975. 